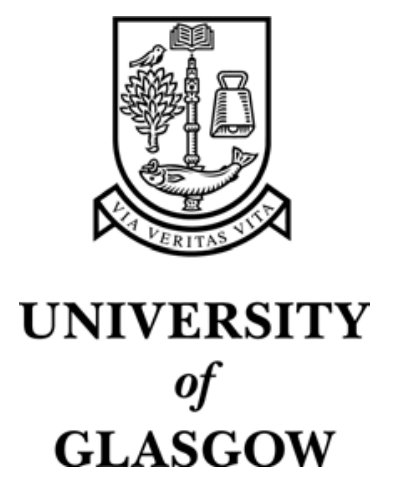

Clayton, P. (2005) Blank slates or hidden treasure? Assessing and building on the experiential learning of migrant and refugee women in European countries. International Journal of Lifelong Education 24(3):pp. 227-242.

http://eprints.gla.ac.uk/2829/ 


\title{
Blank slates or hidden treasure? Assessing and building on the experiential learning of migrant and refugee women in European countries
}

\author{
Pamela Clayton
}

\section{Published in 'International Journal of Lifelong Education', 24 (3), May-June 2005, 227-242, ISSN 0260-1370}

\begin{abstract}
Commonly, the work situation of migrant and refugee women declines notably on arriving in the new country, irrespective of their existing qualifications and even after they have taken accepted qualifications. The primary objectives of this research were to test the hypothesis that women bring to their new countries skills and competences arising from their education, working life and experiential learning, in addition to those learnt in the process of adapting to a new way of life, such as communicative and intercultural competences; and to develop a typology which would facilitate access to appropriate education and training. This process also, crucially, involves vocational guidance and counselling to ensure that women develop goals which are both realistic and desirable to them. To this end an interview schedule was developed and delivered, after adaptations to local circumstances, to 120 women in four countries: Denmark, Germany, the Czech Republic and the UK. This paper presents the detailed findings only from the UK research. The main value of the data gathered is qualitative and the samples used were non-random, but certain patterns emerged which are described in this paper. It was concluded that education and training were usually necessary in the new country but that a much more considered approach needs to be taken to placement on courses. The paper concludes with recommendations for practice by institutions of further education and case studies to illuminate the findings. Four case studies are attached.
\end{abstract}




\section{Introduction: background, rationale and ethos}

The research on which this paper is based was conducted as part of a project supported by the Leonardo da Vinci Programme of the European Union, led by Germany and with partners in Denmark, the Czech Republic and the UK. Bearing the rather unwieldy title, 'Development of European Concepts for the Use of Qualifications and Competencies of Women Immigrants Concerning their Vocational Training', this was later referred to by the team as 'Hidden Treasure', which became the title of two conferences, in London and Hamburg ${ }^{1}$ Several of the team were, or had been, migrants, including the author. Here, however, the term 'Blank Slates' has been used, because so many of the women felt that that was how they were regarded.

For several years there has been concern at European level at an impending skills crisis and the need to upgrade the labour force. More recently schemes have been proposed to give 'green cards' to persuade migrants - the majority of whom are likely to be men - with particularly scarce skills (and from countries which are themselves short of skilled workers) to work in Europe. There are, however, already significant numbers of skilled refugees and migrants in Europe, and they tend to have high rates of unemployment and under-employment. Among these a significant proportion are women.

A recent report (Cabinet Office 2003) found that 'ethnic' 2 minorities were under-represented in the British labour market. Research by NIACE and the Refugee Council suggests that refugees and asylum-seekers with permission to work suffer a very high rate of unemployment (at least $75 \%$ ) (Aldridge and Waddington, n. d.). It is more difficult to find quantitative data on migrant women, and many are not in a position to work, for example, because of caring responsibilities, health or the need first to undertake education and training (Burnett \& Peel, 2001, Community Care 2003a, 2003b and 2003c, Keating et al 2003), but survey evidence suggests that the employment rates of migrant

\footnotetext{
${ }^{1}$ The conference proceedings are available on the web sites of the University of Glasgow and GATE, Hamburg.

${ }^{2}$ Inverted commas are used throughout for the terms 'racial' and 'ethnic' as these terms incorrectly imply fixed boundaries between groups and immutability over time.
} 
women in general are lower than those of non-migrant women; very few women migrants find that they can get a job at the same level as they had in their own country, or that is commensurate with their qualifications; childcare can be very expensive and family networks may be limited or nonexistent, so part-time work or unsociable hours are frequently the only options for those who must work outside the home; those who do find paid work tend to be employed in low-paid sectors such as personal services, hotels and catering and, in the UK, in the care sector or doing voluntary work; refugees, who on average are the most highly qualified newcomers to the UK, suffer the worst employment rates; and the difficulties for refugee women who are able and willing to do paid work in accessing employment, and in particular, employment which uses their skills and qualifications, are particularly acute (Dumper 2002, Bloch 2004).

Some of the barriers are those faced by women in general: discrimination, caring responsibilities, low self-esteem from the lack of value placed on their labour market potential and lack of self-confidence to overcome barriers (Dumper 2002: 38); but the forces of racism, xenophobia and sexism bear down hardest on women from 'ethnic' minorities and particularly on migrants. This applies even to those who arrive with qualifications, experience, a knowledge of English, motivation and high hopes of being able to continue their careers; and much more so to those with experience but no or low formal qualifications and little or no English. In a world where 'employability' is demanded by employers, applicants are required to be 'job-ready' - that is, possessing basic skills, transferable skills and occupation-specific skills to a reasonable level. Also desirable are personal attributes including motivation and disciplined attitudes towards work, learnt and demonstrated principally through prior employment.

Given the official line on 'employability' - that is, that anyone is employable who has all the skills summarised above - one might not expect it to co-exist with discrimination. National origin should be irrelevant provided the person has official permission to work and can do the job, especially in a context of near full employment (which is the case in Denmark and the UK). Many employers, however, appear risk-averse. Outside a particular group (stereotypically, young - but not too young; male - though only in high-status occupations; white; educated - except for the 'over-qualified'; and 
middle class), it is not enough that individuals are 'employable' - they (or advocates on their behalf) have to prove it with much greater effort. The sub-text to 'employable', then, is 'normal' in addition to the other attributes of 'employability' such as the possession of a range of skills. The approach here is, admittedly, a supply-side one, and addresses ways in which migrant and refugee women can become more 'normal' in the eyes of employers. Other approaches are needed to persuade employers that a diverse workforce is profitable rather than risky

Migrant women present a particular challenge both for vocational guidance and educational institutions. The degree of fluency in the language of the new country is an obvious consideration but this is only the beginning. Formal qualifications acquired outside the European Union are often not officially recognised. Even when they are, they are not necessarily accepted by employers. In the case of refugees, the relevant documents may be missing. As for non-accredited competences, these are rarely recognised or valued. This is partly because in many cases women's abilities are still undervalued; partly from a lack of appreciation of the potential of women migrants; and partly because many women themselves do not recognise the value of their skills, abilities and experience. This lack of recognition by women themselves may be because they may not have been valued in their country of origin; they may not have received vocational guidance in the host country; and they may suffer low self-esteem as a result of their experience of immigration. One cause of a negative self-image is precisely the problem of accessing relevant education and desirable employment.

Despite this depressing picture, the starting point for the research was that women migrants and refugees arrive in their new country with much to offer to it. They not only possess learning, both formal and experiential, and competences, from paid, voluntary or domestic work: they also have what could be described as 'tricultural advantage.' Leicester (2001: 61) adapts Mitchell \& Feagin's work on subordinated 'racial' and 'ethnic' groups to ascribed 'bicultural advantage' to women as a group which understands not only 'the mainstream "malestream" but also their experiences as subordinates. Migrant and refugee women in this schema, then, become 'tricultural', in understanding

\footnotetext{
${ }^{3}$ See, for example, the Employers' Forum on Age, www.efa.org.uk, which addresses wider issues than just age.
} 
the new culture as well as the familiar 'male' culture and their own experiences as women. In this way they can perform a valuable role in easing new entrants into the country and acting as cultural mediators, whether formally or informally.

We aimed to discover what talents the women in the survey possessed before their arrival and to suggest ways in which such talents may be brought out and developed through appropriate education, training, support and holistic vocational guidance. The ultimate aim was that women migrants and refugees might be enabled to be at ease in their new society, whether entering the labour market, doing voluntary work, continuing in education or caring for their families or themselves.

We thus wished to collect information from interviewing women migrants in order to create a typology, from which we could generate recommendations for improvement in their access to appropriate education. This typology explicitly avoids stereotyping on 'ethnic' lines. A simplistic and unreflective view of 'ethnic' groups can lead to standardised programmes which ignore important realities and differences in people's lives, goals and values (see Sparks 2002: 117-118).

\section{Definitions and methodology}

Women migrants are here defined as those who have moved to new countries, either as refugees, as independent job-seekers, accompanying husbands or other family members or joining family members already here. It is recognised that each of these reasons for moving has different meanings and implications. It is not assumed that the intention is necessarily to move permanently but certainly for a substantial length of time - long enough for integration to be a sensible goal.

Integration means being at ease in the new country, that is, understanding and knowing how to handle new systems, a different culture and a new set of relationships. Labour market integration means employment or self-employment that allows the individual to live an independent life and fulfil their working potential in a way that gives the individual satisfaction. Vocational education/training means courses or programmes that should assist the student to integrate into the labour market.

Prior qualifications consist of accredited formal learning undertaken outside the European Union. Competences include the skills and abilities deriving from work experience, non-accredited training, 
voluntary work, self-directed study, foreign language acquisition, social and communicative skills, organisational skills, intercultural competence and so on.

We wished to collect information from interviewing women migrants in order to create a typology, from which we could generate recommendations for improvement in their access to appropriate education; but at the same time the interviews had to be intensive and facilitative in order to arrive at hidden or unregarded skills and competences which are, nevertheless, potentially useful and important for employment.

We arrived at two broad research questions:

1) What kinds of qualifications and competences do women migrants possess?

2) What had followed arrival in the new country in terms of education, work and integration? Had these qualifications and competences been recognised or developed by the new country and what if any - examples of good practice appeared?

The most substantial phase of the research consisted of interviews with 120 women migrants in the four participating countries, carried out in 2001. The interviewees were reached through services which specialised in providing guidance and/or education for migrants who were interested in getting jobs or getting better jobs. Most were interviewed in the language of their new country of residence but a few in Germany were accompanied by interpreters.

All the interviews covered the same ground:

- With reference both to the country of origin and the new country, these were: schooling, vocational training, adult education, further and higher education, and any qualifications obtained; work experience and career; capacity and interest in learning new things; other competences they knew they had. Interviewees were also asked to compare their situation in the new country with that in their country of origin in respect of their ease of communication, their place in society and how they saw their future in the new country. 
- With reference to the new country, these were: experience of programmes of integration; languages spoken and levels of competence in speaking, understanding, writing and reading each language; experience and competence in different kinds of communication, including understanding official forms and timetables, using the phone, computer and email, speaking to people one-to-one and in groups, interpreting and translating; ease of communication in a range of circumstances, family, leisure, work and with official agencies; experience of using in a practical way knowledge gained in the country of origin in combination with knowledge gained in the new country.

- Demographic questions, which were placed near the end of the schedule in order not to intimidate those who felt vulnerable, included date and place of birth, and country of birth of parents; civil status and family situation; year of first entry to the new country and any other countries in which interviewees had lived; type of residence permit; approximate annual income; sources of income; religion; 'ethnic' identity; personal history of migration or flight and reasons for moving to a new country; continuing contacts with people in the country of origin; and kinds of contacts in the new country.

The findings presented here, however, are principally from the UK research since detailed results from the other surveys are not available in English. All the women were interviewed in English by the author and this proved advantageous in obtaining the women's own stories. Interviews conducted through interpreters in, for example, Germany, raised questions about the accuracy and completeness of the translations, especially when these were carried out by a family member. On the other hand, the fact that all the British interviewees spoke at least some English means that the sample was not representative.

\section{The findings: 1) treasure trove}

The findings in this section are from the UK research only, since detailed results from the other surveys were not available in English. The women interviewed, 30 in all, lived either in Glasgow or the East End of London. The interviews were carried out in 2001. 


\section{Then and now: education and occupation}

We could not answer in a scientific way to what extent women migrants in general have qualifications, skills and competences (although we assumed that all adults possess the second two if not the first). Further research would be necessary to answer this question definitively, although survey data on refugees already exist and show that a majority are well-qualified and some had highlevel careers before coming here. Women generally have lower educational levels than men, however, and our sample was almost certainly biased towards the better-educated. Two-thirds had attended higher education institutions and one-third had obtained degrees. The majority of those with higher education qualifications had had respected occupations which reflected their qualifications, including university academics, teachers, senior managers and so on. Two without such qualifications had had their own businesses, one as a trader and one as owner of a day care centre (see table 1).

Table 1 Highest level of formal academic education attained before arriving in the UK and former occupation of those who arrived aged 18 or over $(n=27)$

\begin{tabular}{|l|c|l|}
\hline Interviewees' prior formal qualifications & Number & Former occupation \\
\hline Postgraduate degree & 2 & university researcher; assistant programme officer \\
\hline Bachelor's degree & 7 & none; secretary; librarian; university lecturer; \\
\hline Higher Education diploma / teacher training & 5 & senior manager; 2 teachers \\
\hline Advanced level school qualifications & 7 & teachers; senior manager \\
\hline 10 or more years of schooling & & education students; other student \\
\hline Fewer than 10 years of schooling & 27 & dressmaker; none; day care centre head; nurse \\
\hline
\end{tabular}

In table 1, 'none' has different meanings, including no occupation because of domestic responsibilities 
or because the woman left her country before taking a job or completing her education.

The majority had taken courses since arriving in the UK. As well as English classes, many had taken vocational courses and qualifications, for example, in information technology. Six, including three who already had higher academic qualifications, had taken or were taking higher education qualifications, from Higher National Diploma to Master's. Of these, two repeated qualifications they already had and four took higher qualifications.

Despite their prior qualifications and continued use of education, only five could be said to be now working at their full potential, three as project managers, one as a nurse and one as a teacher. Several were unable to access childcare and so were either prevented from getting employment or worked part-time (see Case Study 1, Mary). A former Chief Executive of a trading department was taking in sewing; a former senior manager was working part-time as a care assistant. Neither had dependent children. Nine were doing voluntary work, including one full time (see table 2). 
Table 2 Highest level of formal academic education attained at time of interview (including that undertaken since arriving in the UK) and current occupation $(n=30)$

\begin{tabular}{|c|c|c|}
\hline $\begin{array}{l}\text { Interviewees' current } \\
\text { highest qualification }\end{array}$ & Number & Current occupation \\
\hline Postgraduate degree & 3 & $\begin{array}{l}\text { part-time recreation assistant; full-time voluntary work; } \\
\text { university project manager }\end{array}$ \\
\hline Bachelor's degree & 9 & $\begin{array}{l}\text { part-time bank cashier; PGCE* student; head of NGO; } \\
\text { mother/carer; } 2 \text { job seekers; teacher; NGO project manager; } \\
\text { registered nurse }\end{array}$ \\
\hline $\begin{array}{l}\text { Higher Education diploma / } \\
\text { teacher training / nursing } \\
\text { (sub-degree) }\end{array}$ & 6 & $\begin{array}{l}\text { Master's student/part-time voluntary work; mother; job seeker; } \\
\text { part-time care assistant; student/part-time teacher/translator; } \\
\text { dressmaker }\end{array}$ \\
\hline $\begin{array}{l}\text { Advanced level school } \\
\text { qualifications }\end{array}$ & 5 & $\begin{array}{l}\text { clerk (work placement); mother; } 2 \text { job seekers; student (taking } \\
\text { UK A levels) }\end{array}$ \\
\hline Vocational qualifications** & 5 & $\begin{array}{l}\text { part-time clerk; mother/family worker; care worker; sales } \\
\text { assistant; part-time NGO administrative assistant }\end{array}$ \\
\hline $\begin{array}{l}10 \text { or more years of } \\
\text { schooling }\end{array}$ & 1 & part-time cleaner \\
\hline $\begin{array}{l}\text { Fewer than } 10 \text { years of } \\
\text { schooling }\end{array}$ & 1 & mother \\
\hline & 30 & \\
\hline
\end{tabular}

* post-graduate certificate of education (for teachers)

** including National Vocational Qualifications, Royal Society of Arts, City and Guilds, BTEC

The reasons for this lowering of occupational status are varied and some lie in areas such as trauma, poverty, poor housing and so on. These require support from a range of agencies. Certainly a good command of English is helpful and so are qualifications; against these are: 
- discrimination by employers (one woman had had several interviews but felt that employers thought that there would be resentment at being managed by someone who was a woman, a foreigner and a refugee - another has taken a range of relevant qualifications but still does not have a 'proper job - see Case Study 2, Aminata);

- lack of experience seen as relevant (one had Pitmans qualifications, had worked as a secretary and owned her own business, but her British qualifications were undervalued as she did not have work experience in the UK; she could not get a secretarial job and was advised to go into care work as 'there are always jobs in this sector' - see Case Study 3, Carmel);

- insufficient knowledge of the system and the culture (one had attended many interviews and could not understand why she did not get a job until someone pointed out that it was not wise at that time to wear trousers for interviews);

- poor access to informal networks (one of the interviewees would have been very happy to work in a factory, but such jobs are rarely advertised).

\section{Linguistic and communicative competence}

The women interviewed spoke between them a great number of languages. A mere half-dozen had only two languages (mother tongue and English); four knew six or more languages; and twenty knew between three and five languages, many of these at a high level of competence. The biggest category of women in the British survey came from Africa and when India, Pakistan, Bangladesh, Sri Lanka and the Pacific are added it is to be noted that almost two-thirds originate in the Commonwealth (see table 3). 
Table 3 Region of origin $(n=30)$

\begin{tabular}{|l|c|}
\hline \multicolumn{1}{|c|}{ Region of origin } & Number \\
\hline Africa (including East African Indians) & 13 \\
\hline Eastern and Central Europe including the former Soviet Union & 6 \\
\hline India, Pakistan, Bangladesh, Sri Lanka & 5 \\
\hline Middle East & 4 \\
\hline Pacific & 1 \\
\hline South America & 1 \\
\hline
\end{tabular}

Most displayed a good level of communication in English, though women interviewed in the other countries were much less likely on arrival to have such competence in Czech, Danish or German. Over half arrived with a long acquaintance with English, either as a school subject and/or through living in another anglophone country. For many of the women from the former British colonies, especially in Africa, English was an official national language and for a few an equal first language. Those from eastern Europe and the former Soviet Union were more likely to arrive with no prior knowledge of English but these had learnt to communicate very quickly.

Predictably, reading English was found to be the easiest of the four skills and writing the hardest. Understanding English accents was something of a handicap for more recent arrivals; but all felt their spoken English was either very or reasonably good, impressions confirmed by the interviewer (see table 4). 
Table 4 Competence in English, as estimated by interviewees in discussion with the interviewer $(\mathbf{n}=\mathbf{3 0})$

\begin{tabular}{|l|c|c|c|}
\hline Level of competence & Very good & Reasonably good & Not very good \\
\hline Spoken English & 17 & 13 & 0 \\
\hline Understanding of spoken English & 17 & 12 & 1 \\
\hline Written English & 13 & 14 & 3 \\
\hline Ability to read English & 19 & 10 & 1 \\
\hline
\end{tabular}

Communicative competence and confidence were also found to be high. The majority felt they were very good or reasonably good at writing letters (23), understanding timetables (26), understanding official forms (25), using the telephone (29), using a computer (24), using email (16), speaking oneto-one (29) and speaking to groups (27). In addition many had done translating (14) or interpreting (21) on behalf of fellow migrants. Overall, almost all (28) felt that they communicated very or reasonably well in the UK generally; at work (23); in their leisure activities (25); and with state authorities (25), though only half of these felt very confident. One asylum-seeker, however, had helped her husband take legal action against the Benefits Agency and won.

\section{Other competences}

Women, when pressed, admit to a range of non-accredited skills and abilities arising out of their life experience, such as time management, money management, relating well to people, managing conflict, helping new migrants, cooking, sewing, driving and so on. In addition, the very fact of moving to a new land involves skills, such as learning a new language and culture, negotiating new institutional arrangements, battling bureaucracy and so on. The only ones, however, who confidently produced a positive self-assessment had been through a formal vocational guidance process.

Generally the women found it difficult without assistance to recognise or offer to the interviewer any competences not associated with education or paid work that they had undertaken. 


\section{The findings: (2) blank slates - hidden treasure remains buried}

As for the second research question, the extent and willingness of host country institutions to recognise and assist in the development of women migrants' potential, the broad answer is very mixed. Location is important. Some areas have many more facilities and range of courses than others, even within the same city. The dispersal policy for asylum-seekers found some local authorities and services unprepared. It is not easy to find information of the rights to education and training of migrants, asylum-seekers and refugees, and there is a certain amount of local discretion in this field (but not in rights to employment).

There are however examples of good practice in attempting to change this situation, particularly in the UK. There are higher and further education providers who carry out the Assessment/Accreditation of Prior (Experiential) Learning ( $\mathrm{AP}(\mathrm{E}) \mathrm{L})$ but this is a lengthy and expensive process and very far from universally used. The Refugee Councils and a range of refugee and migrant or 'ethnic' minority agencies in the NGO sector do good work but with limited and insecure funding. Provision of classes and guidance services in Glasgow and London certainly exists but is inadequate for the needs of migrant women; the existence of substantial migrant communities in London is potentially helpful, in that word-of-mouth is a powerful mode of publicity for services and there is a critical mass in many language groups which might facilitate the teaching of ESOL. The great number of languages spoken, however (apparently 150 in the East End of London alone), shows the problems of devising appropriate provision.

However, one of the biggest problems is the frequent failure to place women on a course at a level which is appropriate to their stage of learning and to ensure her progression. This is partly due to a shortage of resources. One young woman was offered a business studies course in one area of London but when she moved to the East End this was not available and there were no spare places on advanced ESOL courses. There is also a propensity to treat women migrants as blank slates and set them to begin again at the beginning. When this was mentioned in the interviews, all the women said that they had experienced this. (See Case Study 4, Satu.) 
A fundamental problem for many women migrants was highlighted by the German research - lack of access to information and guidance. This meant that they knew little or nothing about what German language courses existed, about their legal position vis-à-vis access to the labour market, about recognition of their diplomas, or about further education and training. As a result, those who did take courses sometimes took ones which led nowhere for them. Many did not find German language courses, or found ones that were too easy, too intensive or too expensive. In Denmark there is a welldeveloped programme for the integration of refugees, though migrants have had until recently to make their own way. The programme includes intensive classes in Danish over several years. Although refugees have counsellors to go to, migrants have no equivalent access to information and guidance. The Czech Republic is the least developed in this field, and indeed has the great challenge of developing adult education and guidance for its own citizens as well as for migrants.

Everywhere, for women with academic or professional qualifications, the problem is to get them recognised, failing which a lengthy and expensive process of re-qualification is required. Many give up through lack of information, of money and of support and through declining confidence as years of unemployment or under-employment mount up.

\section{Conclusions}

Following the completion of the survey, the findings were used, firstly to develop a typology of women migrants and secondly to make recommendations for their placement on education and training courses.

\section{Towards a typology of women migrants}

From the point of view of vocational education, a woman migrant entering education encompasses several variables:

- knowledge of the language (from nil to perfect)

- familiarity with the new culture (from nil to full)

- paper qualifications (from nil to postgraduate - or missing documents) 
- work experience - quantity (from nil to extensive)

- work experience - level (from unskilled to managerial/professional)

- life experience (from positive to traumatic)

- current life situation (this has implications for the timing of classes, student support services etc.)

All these variables should be taken into account before placing a woman on a programme.

Although each woman is unique, a large educational provider should be able to place her in a programme which recognises her as a whole person, by putting her at different levels for different aspects, e.g. language, vocational training, cultural orientation. In practice, however, many women will fall into one of several groups, defined by their primary needs. Examples (not a complete list) are:

1. women with no knowledge of the language or culture, no paper qualifications and unskilled/semiskilled work experience - primary needs: basic language training and cultural orientation; vocational guidance in their own language;

2. women with basic knowledge of the language and culture, no paper qualifications and unskilled/semi-skilled work experience - primary needs: intermediate language training and vocational education in fields which suit their preferences and perhaps draw on their life/work experience, paper qualifications; vocational guidance including APEL;

3. women with adequate knowledge of the language and culture, no paper qualifications and unskilled/semi-skilled work experience - primary needs: vocational education, paper qualifications, language support; vocational guidance including APEL;

4. women with no knowledge of the language or culture, but with paper qualifications and mediumto high-level work experience - primary needs: intensive language training, cultural orientation, recognition of qualifications; vocational guidance including APL and APEL in their own language; 
5. women with reasonable knowledge of the language and culture, paper qualifications but no work experience - primary needs, work placement, language support; vocational guidance including APL and APEL;

6. women with a good knowledge of the language and culture, missing paper qualifications and medium- to high-level work experience - primary needs: APEL, APL or re-qualification, work experience in the new country;

7. women with a good knowledge of the language and culture, paper qualifications and medium- to high-level work experience - primary needs: recognition of qualifications or re-qualification, work experience in the new country, APEL.

Primary needs will change as she completes each stage of a programme. For example, a woman who starts in group 1 above may then become part of group 2. Special cases might exist, such as women with excellent knowledge of the language but no or low qualifications and/or skills. Placement should be based on her primary needs, not on the fact that she is an migrant. Whatever stage she is at, vocational guidance plays a vital role in order to help her assess her needs and assist her in choosing the most appropriate course of action.

\section{Towards educational programmes for women migrants}

Following on from the typology, programmes on offer should include elements which meet the primary needs outlined above.

- language training: for beginners (level 1); intermediate (level 2); advanced (level 3); plus language support to accompany vocational education;

- vocational education: basic; intermediate; advanced;

- cultural orientation: in mother tongue for those with little or no knowledge of the new language; in the new language for those with some knowledge of it;

- vocational guidance at all stages;

- mentoring; 
- APL and APEL;

- process of recognition of qualifications;

- adaptation/updating of qualifications;

- culturally-sensitive student support services;

- assessment procedures to ensure that women are placed at the correct level;

- opportunities for work placements.

Such a programme might be run in a single institution or split among several. Guidance is essential to help women who have to move between institutions.

\section{General recommendations}

These recommendations for services which could assist women migrants are based on examples of good practice in the four countries in the project:

- Programmes of integration, involving information about education, the labour market and cultural norms in the new country, for migrants who want them (but no sanctions against those who do not);

- Expert assessment of language competence and appropriate courses where necessary;

- Integration of linguistic and vocational education, such that these take place together, but without a narrow focus on, for example, 'business English', and inclusion of work placements;

- Use of Accreditation of Prior Learning (APL) and of Prior Experiential Learning (APEL), available in all institutions of further and higher education, so that educational providers may recognise women's existing level of education, skills and abilities rather than treating them as blank slates;

- Universal access to vocational guidance services offering paths to education/training, employment and self-employment, and undertaking APL and APEL in order to assist employers (these should be available to all, whether migrant or not). 
Our typology, the variables, the suggested programme elements and the recommendations do not differentiate between refugees and economic or family migrants. Where there are legal or other differences between these categories, services clearly need the kind of in-depth knowledge which allows them to give appropriate guidance.

Despite many negative experiences, most of the women interviewed in the UK felt that they were safe here and their children would get a good education. A few had had much better fortune than they expected, including one who had received refugee status within a few months of arriving and shortly after that was able to access grants to start her own NGO to help other women. Length of residence and level of English were more usual helpers in gaining worthwhile jobs. Normally, however, the passage from arrival to integration takes far too long and much talent and optimism is wasted in the process.

\section{Case studies}

Please note that certain details have been suppressed or changed in the case studies of women refugees and others who did not wish to be identified. These changes/omissions do not detract from the substantive material. More case studies can be found at: http://www.gla.ac.uk/rg, Mainstreaming vocational guidance for refugees and migrants.

\section{Case study 1}

Mary is 37 years old and comes from Africa. She is a Christian and identifies herself as a black African. She came to the UK in 1986 at the age of 24. At the time of a revolution in her country, her husband had been in danger and he arrived in the UK in 1985 as a refugee. She followed him the next year. It took until 1993 to obtain Exceptional Leave to Remain (ELR). They are now waiting for indefinite leave to remain, that is, permanent residence in this country. She lives with her husband and three children, aged ten, eight and four, all born in the UK.

Her schooling lasted ten years but she did not obtain any qualifications. Having left school at thirteen, she learned dressmaking at home from a skilled woman and then worked at home as a dressmaker 
until she left. She didn't have modern machinery so it was very hard to make a lot of money. Most of her customers were friends or family so she didn't feel that she could charge very much anyway.

In the UK she found work fairly quickly in a small factory making suits and so on and expanded to making other clothes. It took one year on-the-job training because she had no experience of modern machines. The factory then closed, she was unemployed for a year and then found a similar job which lasted for two years until that factory also closed. She spent another year unemployed and then became pregnant and because it was too difficult with a baby to combine work and motherhood, she stayed at home for two years after giving birth. She then obtained another machinist job which lasted between two and three years, then spent another year at home. After her third baby she tried very hard to get another machinist job but the only job she could get was cleaning. She earns very little, but her husband works for Ford and as long as he has this job their financial situation is acceptable.

\section{Case study 2}

Aminata is thirty. She is a Muslim from Africa. She identifies herself as a black African. She and her family left their country because of civil war. At that time, everyone was fleeing to countries where there was no war, and she went with her parents and siblings to a neighbouring country for a few months. There was only enough money to send one of them to the UK and it was very hard to get visas. Aminata was the one chosen because she was the oldest child; the others weren't old enough. They chose the UK for her because a lot of her family were already here. Her parents and siblings are now in a third African country and she has not seen them since 1993 when she arrived in the UK. She applied for refugee status as soon as she arrived. After two months she was given ELR and after waiting for seven years she received Indefinite Leave to Remain (ILR). That was in May 2000 and it means that she has refugee status and so she can remain permanently.

Within three months of her arrival she began her education here by taking English for Speakers of Other Languages (ESOL) at a college of Further Education (FE). Secondly, she took City \& Guilds qualifications in English, maths, IT, science and business studies. Following that she went to a college of FE and passed the General Certificate of Secondary Education (GCSEs) in three subjects, English, maths and science. Then she took a year-long business study course, also at the college of FE, which 
included English, maths, IT, and business studies. She then did English and computing for a further six months followed by six months computing course at a vocational training NGO. She has had two work placements. The first, as a receptionist at a university, lasted one week and was in 1994, the year following her arrival in the UK. Her current work placement has lasted almost a year; she is working at a local association for people from her country of origin. She earns very little.

\section{Case study 3}

Carmel is 39 years old and married with three children aged sixteen, fourteen and ten. She is a Christian and identifies herself as mixed (African and Indian). She and her husband came to the UK in 1994 as political refugees. She has Indefinite Leave to Remain.

She has obtained the East African Certificate of Education (formerly the Cambridge Certificate) at $\mathrm{O}$ level after eleven years schooling in her own country and then moved to a neighbouring country in 1978 to attend secretarial college for two years. There she obtained UK qualifications (Pitmans). On graduating she worked as a secretary in several organisations, first in the country where she got her qualifications, and then in another African country when her husband got a job there. They moved back to their home country and after working two more years as secretary Carmel opened a day care centre. In 1986 she qualified as a nursery nurse (equivalent to the relevant British qualification); and 1993 she took a six-month public relations (PR) course in Berlin. In 1994 she and her family fled to the UK.

Since coming to the UK, she has taken a part-time computing course, gaining certificates for proficiency in various computer programmes such as Word and Excel. She found that her Pitmans qualifications, though British, were undervalued as she did not have work experience in the UK. She descended the social ladder on coming to the UK, abandoning a better standard of life. It took her two years to find a job. She could not get a secretarial job. She began by doing voluntary work in the care sector, then got temporary jobs while permanent staff were on leave, and finally got a permanent post. She now earns a good salary caring for African people with HIV or AIDS. She was about to start a part-time course in business and computer studies, and is considering starting up another business, possibly training young people. 


\section{Case study 4}

Satu is 36 years old, a Nigerian Muslim, and married with four children aged ten, eight, six and two. She is able to stay in the UK as her husband has a temporary job here, which will become permanent after four years. She identifies herself as a Black African. She arrived in the UK in 1999. Her husband had previously worked in Saudi Arabia for eight years and Satu spent a year there with him (1997-98) before returning to Nigeria for a further year. Then her husband got a job in the UK to give their children better educational opportunities than exist in Saudi Arabia, especially since their eldest son is deaf.

She had fifteen years of schooling, gaining the West African exam board higher level certificate. She then went to teacher training college and obtained the Nigerian Certificate in Education (NCE) at Grade II. She became a primary school teacher but after one year she returned to college to further her education and passed at Grade I to become a secondary school teacher. She subsequently taught economics and business studies for eight years.

She has already taken courses in the UK, a computer course (Word level 1), a supervisors management course (NVQ level 3) and a health assistant's course. She has a part-time job through an agency, as a carer for elderly people. She has descended from having a middle-class, very respectable job in Nigeria to suffering first unemployment and now a very low-paid part-time job; she would like to do a degree but she has been told that she must re-take her school qualifications. Nevertheless she is determined to succeed and to learn whatever is necessary in order to be gainfully employed; and she sees a bright future in the UK, even though it may take a long time.

\section{Acknowledgements}

I would like to end by thanking all these admirable women who agreed to be interviewed and wish them all well in their futures. I hope that, in time, they all fulfil their wishes - but some of the women were asylum-seekers whose claims, sadly, were likely to be refused. I would have wished them all to be able to stay and benefit themselves and their new country with their talents, hard work, determination and dreams. 


\section{References}

Aldridge, F. and Waddington, S., (n. d.), Asylum Seekers' Skills and Qualifications Audit: Pilot project (2001), (Leicester: NIACE).

Bloch, A., (2004), Refugee Women and Employment: Barriers to integration. Refugee Women's News, Issue 27, March-April 2004.

Burnett, A. and Peel, M., (2001), Health needs of asylum-seekers and refugees. British Medical Journal, 322, 544-547. Available at bmj.com/cgi/reprint/322/7285/544.pdf. Accessed 16/08/04.

Cabinet Office, (2003), Ethnic Minorities and the Labour Market.

Community Care, (2003a), Isolated by Gender. Online. Available at

www.communitycare.co.uk/articles/article.asp?liarticleid=34105. Accessed 16/08/04.

Community Care, (2003b), The Long Walk to Freedom. Online. Available at www.communitycare.co.uk/articles/article.asp?liarticleid=41350. Accessed 16/08/04.

Community Care, (2003c), The Voice of Experience. Available at www.communitycare.co.uk/articles/article.asp?liarticleid=31322. Accessed 16/08/04.

Dumper, H., (2002), Missed Opportunities: A skills audit of refugee women in London from the teaching, nursing and medical professions, (London: Greater London Authority). Available at www.london.gov.uk/approot/mayor/refugees/docs/skills_rpt.pdf. Accessed 16/08/04.

Keating, F., Robertson, D. and Kotecha, N., (2003), Ethnic Diversity and Mental Health in London: Recent developments. King's Fund Working Paper. Available at www.kingsfund.org.uk/pdf/Ethnic\%20Diversity\%20and\%20Mental\%20Health\%20in\%20London.pdf Accessed 16/08/04.

Leicester, M., (2001), Two decades of feminist thought - and beyond. International Journal of Lifelong Education, 20, 55-62.

Sparks, B., (2002), Epistemological and methodological considerations of doing cross cultural research in adult education. International Journal of Lifelong Education, 21, 115-129. 